\title{
GLYCOSYLATION OF THE BOVINE CORONAVIRUS HEMAGGLUTININ PROTEIN
}

\author{
Brenda G. Hogue and David A. Brian \\ Department of Microbiology \\ University of Tennessee \\ Knoxville, TN 37996-0845
}

\section{ABSTRACT}

The bovine coronavirus hemagglutinin protein gp140 is composed of disulfide-linked subunits of $65 \mathrm{kDa}$. This protein was further characterized with regard to its glycosylation. The glycosylated subunits of the protein are polypeptides having a molecular mass of $42.5 \mathrm{kDa}$. Both subunits appear to be processed to the same extent by the addition of $\mathrm{N}-$ linked oligosaccharides. Each subunit on the mature virion has 6-7 high mannose and 3-4 complex type carbohydrate chains attached to it.

\section{INTRODUCTION}

At least three structural proteins have been identified for all characterized coronoviruses (Siddel1, 1982). They are a phophorylated nucleocapsid of $50-60 \mathrm{kDa}$, a glycosylated matrix-like protein of 23-29 kDa, and a peplomeric glycoprotein of 150-200 kDa. For the mammalian coronaviruses that hemagglutinate, including the porcine hemagglutinating encephalomyelites virus (Callebant and Pensaert, 1980), the bovine coronavirus (BCV) (Hogue et al., 1984; King and Brian, 1982), and the human respiratory coronavirus 0C43 (Hogue et al., 1984; Hogue and Brian, 1986), an additional structural protein has been described. The fourth protein in the bovine coronavirus is a glycoprotein of $140 \mathrm{kDa}$ which is comprised of disulfide-linked subunits of $65 \mathrm{kDa}$ (Hogue et al., 1984; King et al., 1982). This additional protein appears to be the virion hemagglutinin (King et al., 1985). Consistent with this conclusion is the finding that the nonhemagglutinating mouse hepatitis coronavirus strain $\mathrm{A} 59$, which is otherwise antigenically closely related to the mammalian hemagglutinating coronaviruses, has no molecular counterpart to this protein (Hogue et al., 1984). However, molecular counterparts of each of the remaining three major structural proteins of MHV A59 have been identified (Hogue et al., 1984). The present investigation was undertaken to further characterize the additional structural protein gpl40 of the bovine coronavirus (BCV) with regard to its glycosylation. 


\section{MATERIALS AND METHODS}

\section{Virus and Cells}

The Mebus strain of the bovine coronavirus and the human rectal carcinoma cell line HRT-18 were used throughout this study. The procedures for virus plaque purification and growth have been described (Hogue et al., 1984). Viral proteins were labeled by the addition of $400 \mathrm{uCi}$ of either $3 \mathrm{H}$-amino acids $(150-200 \mathrm{mCi} / \mathrm{mg}$ ICN), $3 \mathrm{H}-\mathrm{glucosamine}$ (5-15 Ci/mmole) or $3 \mathrm{H}$-mannose $\left(22 \mathrm{Ci} /\right.$ mmole) per $150 \mathrm{~cm}^{2}$ flask following adsorption of virions.

\section{Analysis of Proteins}

The procedures for polyacrylamide gel electrophoresis and immunoblotting have been described. Preparation and characterization of monospecific rabbit antiserum against the BCV gp65 subunits was previously described. Virus was harvested and purified by isopycnic sedimentation in continuous sucrose gradients as previously described (Hogue et al., 1984). To examine intracellular proteins, whole cell lysates were prepared by washing infected or control monolayers in $60 \mathrm{mM}$ petri dishes with cold phosphate-buffered saline (PBS), and cells were scraped into PBS and pelleted by centrifugation at 2,000 rpm. The pellets were diluted in $100 \mathrm{ul}$ sterile distilled water, sonicated at 50 watts for 10 seconds in a bath sonicator, and stored at $-80^{\circ} \mathrm{C}$. Equal volumes of lysate and $2 \mathrm{X}$ sample treatment buffer $(0.250 \mathrm{~m}$ Tris-hydrochloride, $\mathrm{pH}$ $6.8,4 \%$ SDS, $10 \mathrm{M}$ urea, bromophenol blue) were mixed and heated at $100^{\circ} \mathrm{C}$ for 5 minutes prior to electrophoresis.

Inhibitors and Enzymes

Tunicamycin (Sigma) was used at final concentrations of 0.5 to 10 $\mathrm{ug} / \mathrm{ml}$. Monensin (Calbiochem) and swainsonine (Calbiochem) were used at final concentrations of $10^{-6}$ or $10^{-7} \mathrm{M}$ and $5-500 \mathrm{ng} / \mathrm{ml}$, respectively. All inhibitors were included in the medium used to refeed infected or control cells. Cells were maintained in this medium until harvested.

Endo-H (Division of Laboratories and Research, N.Y. State Department of Health Albany, New York) was used at a final concentration of $12.5 \mathrm{mu} / \mathrm{ml}$. For digestions with $\mathrm{N}-$ glycanase (Genzyme, Boston), concentrations between 0.87 and $35 \mathrm{u} / \mathrm{ml}$ were used.

\section{RESULTS}

Inhibition of Glycosylation by Tunicamycin

The effect of tunicamycin on the intracellular synthesis of gp 140 was examined by analyzing the proteins synthesized in the presence of different concentrations of the inhibitor of N-1inked glycosylation. Only one band with a molecular mass of $42.5 \mathrm{kDa}$ was identified (Fig. 1). Both nonglycosylated subunits are apparently the same size since only one polypeptide species could be identified using monospecific antiserum against the gp65 subunits.

\section{Deglycosylation using $\mathrm{N}-\mathrm{g} 1 \mathrm{ycanase}$}

The enzyme $\mathrm{N}-\mathrm{glycanase}$ was used to confirm the results obtained with tunicamycin. This enzyme hydrolyzes the glucosylamine linkage of 


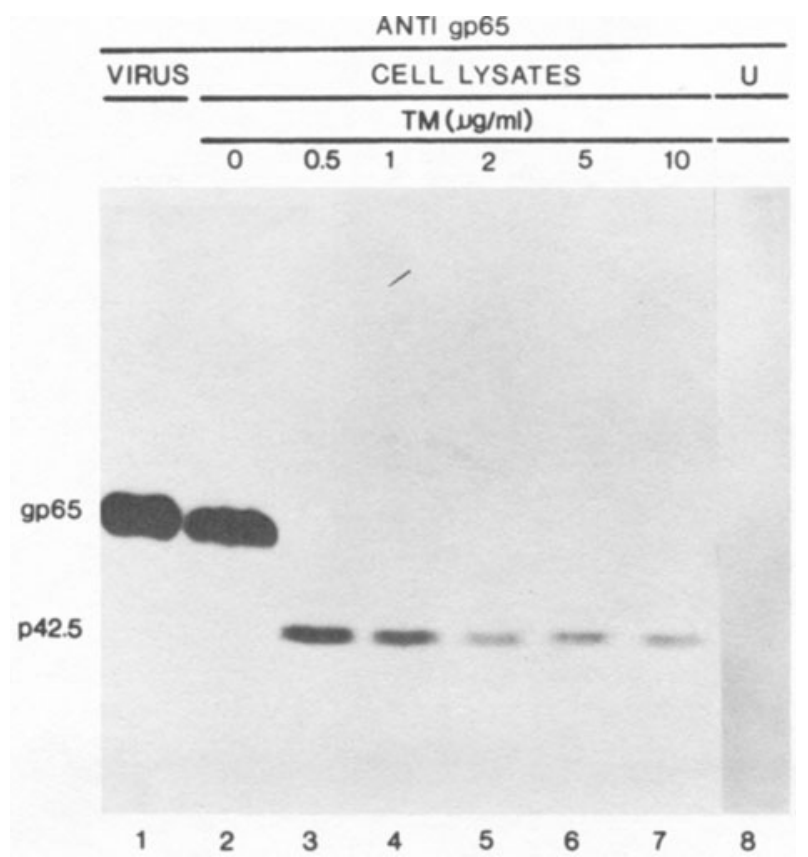

Figure 1. Effect of tunicamycin on the synthesis and processing of gp140. Lane 1: purified virus. Lanes 2-7: whole cell lysates of infected cells maintained respectively in the presence of $0,0.5,1,2,5$, and 10 ug tunicamycin (TM) per m1. Lane 8: uninfected cell lysate (U) from cells maintained in the presence of 10 ug per ml TM. All lanes were electrophoresed on an $8 \%$ polyacrylamide gel in the presence of $2 \%$ 2-mercaptoethanol and immunoblotted with antiserum against the gp65 subunits.

both high mannose and complex types of $\mathrm{N}$-linked oligosaccharides. Following treatment of purified virions with $\mathrm{N}-$ glycanase, only one band was observed which migrated slightly slower than the nonglycosylated species produced in the presence of tunicamycin (Fig. 2). This suggests that other modifications may be present on the protein.

\section{Digestion with Endoglycosidase-H}

In order to determine if the $\mathrm{N}-1$ inked oligosaccharides on the gp65 subunits are of the high mannose or complex type, purified

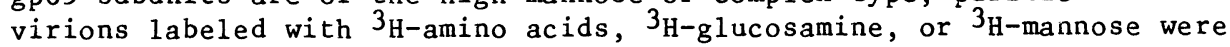
treated with endo-H. Only high mannose type chains are removed by this enzyme. The gp65 subunits were only partially susceptible to endo-H digestion (Fig. 3). This was confirmed by immunoblotting with antiserum specific for the gp65 subunits. The data indicate that the mature virion gp 140 contains oligosaccharides of both the mannoserich and complex type. Following endo-H digestion, the gp65 subunits comigrated with the nucleocapsid protein pp52. Therefore, the carbohydrates removed by endo-H digestion contribute 10-13 $\mathrm{kDa}$ to the molecular weight of the protein. The $10 \mathrm{kDa}$ of mass remaining on the molecules must be contributed by complex chains and possibly other modifications. 


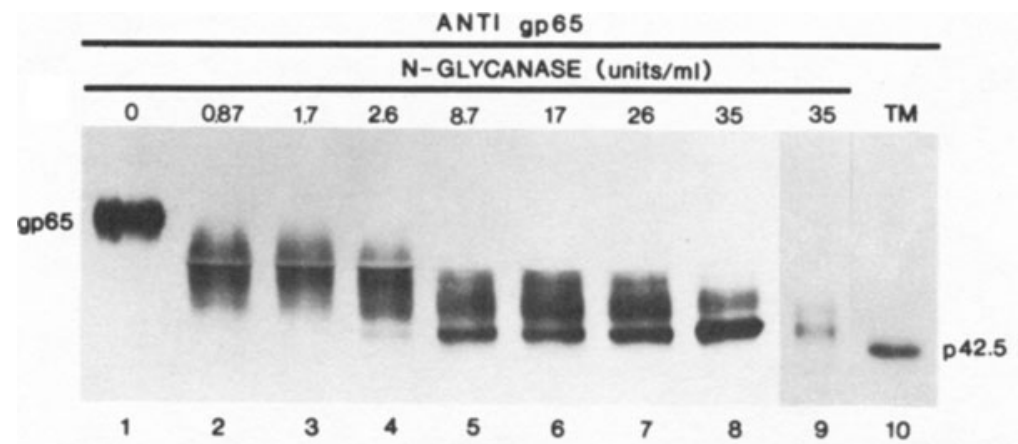

Figure 2. Removal of $\mathrm{N}$-1inked oligosaccharides on the gp65 subunits with N-glycanase. Lanes 1-9: purified virus treated with Nglycanase at $0,0.87,1.7,2.6,8.7,17,26$, and 35 units per $\mathrm{ml}$, respectively, electrophoresed on an $8 \%$ polyacrylamide gel, and immunoblotted with anti-gp65 serum. Lane 10: infected whole cell lysate from cells treated with 1 ug tunicamycin (TM) per ml.

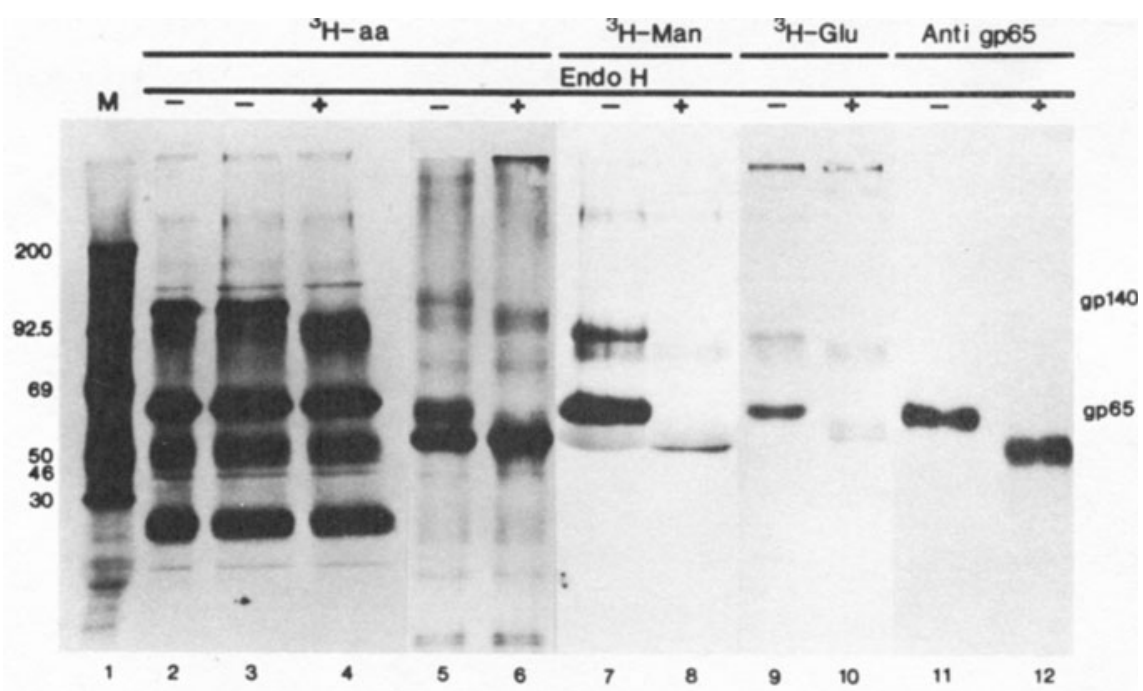

Figure 3. Digestion of virion gp65 subunits with endoglycosidase H. Lane 1: molecular weight markers. Lanes 2-10: purified virus radiolabeled with $3 \mathrm{H}$-amino acids (lanes 2-6), $3 \mathrm{H}$-mannose (lanes 7 and 8 ) or $3 \mathrm{H}-\mathrm{glucosamine}$ (lanes 9 and 10 ) was incubated with $(+)$ and without $(-)$ endo $H$ and immunoblotted with anti-gp65 serum. Polyacrylamide concentrations are $5-15 \%$ for lanes $1-4$ and $8 \%$ for lanes 5-12. All samples were electrophoresed in the presence of 2-mercaptoethanol except lanes 2-4. 


\section{DISCUSSION}

The data demonstrate that the $\mathrm{BCV}$ gp140 is similar to peplomeric glycoproteins of MHV A59 (Niemann and Klenk, 1981) and BCV (Hogue and Brian, unpublished data) in that it has $\mathrm{N}$-linked oligosaccharides of both the mannose-rich and complex types attached to it. This is in contrast to the matrix proteins of MHV A59 (Holmes et al., 1981; Niemann and Klenk, 1981; Niemann et a1., 1982; Rottier et al., 1981) and BCV (Niemann and Klenk, 1981; Lapps et al., this volume) which are glycosylated with 0-1inked oligosaccharides.

Based on our molecular weight determinations, the carbohydrate portion of gp140 accounts for approximately $35 \%$ of the protein's molecular weight. This composition is similar to that of the peplomeric protein of IBV which has approximately $30 \%$ of its molecular weight contributed by glycosylation (Binns et al., 1985; Stern and Lefton, 1984). In contrast, gp140 differs from the other two BCV and MHV glycoproteins. Approximately 17\% of MHV A59's peplomeric glycoprotein and $13 \%$ of its matrix protein are contributed by attached carbohydrate (Niemann and Klenk, 1981). Assuming that the oligosaccharide chains of the BCV gp140 resemble N-linked chains of other glycoproteins, which usually have molecular weight values of approximately 2,000 for mannoserich and 2,500-3,500 for complex chains (Klenk and Rott, 1982), gp140 can be calculated to have 6-7 high mannose, and 3-4 complex chains on each gp65 subunit. Other modifications such as acylation may be present and therefore may affect these estimates.

The subunits (gp65) of gpl40 appear to be processed identically and, at no point did there appear to be two different subunits. This suggests that gp140 may be synthesized by disulfide linkage of identical subunits. Experiments are currently in progress to determine if the subunits are indeed identical, and at this time the possibility that the subunits are the result of cleavage of a precursor polypeptide to produce nonidentical subunits of the same size cannot be exclused. Based on the size of the nonglycosylated protein observed in the presence of tunicamycin, a gene of $1.15 \mathrm{~Kb}$ would be required to code for one of the gp140 subunits. Studies currently in progress in our laboratory are focused on determining the actual size of the gene for gp140, and where it is located within the BCV genome.

\section{ACKNOWLEDGEMENT}

This work was supported by grant AI-14367 from the National Institute of Allergy and Infectious Diseases, by grant 82-CRSR-2-1090 from the U.S. Department of Agriculture, and in part by a grant from the National Foundation for Ileitis and Colitis, Inc.

\section{REFERENCES}

Binns, M. M., M. E. G. Boursne11, D. Cavanagh, D. J. C. Pappin, and T. D. K. Brown. 1985. Cloning and sequencing of the gene encoding the spike protein of the coronavirus IBV. J. Gen. Virol. 66: 719-726.

Callebaut, P. E., and M. B. Pensaert. 1980. Characterization and isolation of structural peptides in hemagglutinating encephalomyelitis virus. J. Gen. Virol. 48: 193-204. 
Hogue, B. G., B. King, and D. Brian. 1984. Antigenic relationships among proteins of bovine coronavirus, human regulatory coronavirus OC43, and mouse hepatitis coronavirus A59. J. Virol. 51: 384-388.

Hogue, B. G., and D. A. Brian. 1986. Structural proteins of human respiratory coronavirus 0C43. Virus Res. 5: 131-144.

Holmes, K. V., E. W. Doller, and L. S. Sturman. 1981. Tunicamycin resistant glycosylation of a coronavirus glycoprotein: Demonstration of a novel type of viral glycoprotein. Virology 115: 334-344.

King, B., and D. A. Brian. 1982. Bovine coronavirus structural proteins. J. Virol. 42: 700-707.

King, B., B. J. Potts, and D. A. Brian. 1985. Bovine coronavirus hemagglutinin protein. Virus. Res. 2: 53-59.

Klenk, H.-D., and R. Rott. 1981. Cotranslational and posttranslational processing of viral glycoproteins. Curr. Top. Microbiol. Immuno. 90: 19-48.

Niemann, H., B. Boschek, D. Evans, M. Rosing, T. Tamura, and H.-D. Klenk. 1982. Posttranslational glycosylation of coronavirus glycoprotein El: inhibition by monensin. EMBO J. 1: 1499-1504.

Niemann, H., and H.-D. Klenk. 1981. Coronavirus glycoprotein E1, a new type of viral glycoprotein. J. Mol. Biol. 153: 993-1010.

Rottier, P. J. M., M. C. Horzinek, and B. A. M. van der Zeijst. 1981 . Translation of three mouse hepatitis virus (MHV-A59) subgenomic RNAs in Xenopus laevis oocytes. J. Virol. 38: 20-26.

Siddell, S., H. Wege, and V. ter Meulen. 1982. The structure and replication of coronaviruses. Curr. Top. Microbiol. Immunol. 99: 131-163.

Stern, E. F., and B. M. Sefton. 1984. Coronavirus multiplication: the location of genes for the virion proteins on the avian infectious bronchitis virus genome. J. Virol. 50: 22-29. 